\title{
Tudor and its domains: germ cell formation from a Tudor perspective
}

\author{
Travis THOMSON, Paul LASKO* \\ Department of Biology, McGill University, Montreal, Quebec, Canada H3A 1B1
}

\begin{abstract}
In many metazoan species, germ cell formation requires the germ plasm, a specialized cytoplasm which often contains electron dense structures. Genes required for germ cell formation in Drosophila have been isolated predominantly in screens for maternal-effect mutations. One such gene is tudor $(t u d)$; without proper tud function germ cell formation does not occur. Unlike other genes involved in Drosophila germ cell specification tud is dispensable for other somatic functions such as abdominal patterning. It is not known how TUD contributes at a molecular level to germ cell formation but in $t u d$ mutants, polar granule formation is severely compromised, and mitochondrially encoded ribosomal RNAs do not localize to the polar granule. TUD is composed of 11 repeats of the protein motif called the Tudor domain. There are similar proteins to TUD in the germ line of other metazoan species including mice. Probable vertebrate orthologues of Drosophila genes involved in germ cell specification will be discussed.
\end{abstract}

Keywords: Drosophila, tudor, germ cells, germ plasm, Tudor domains.

\section{INTRODUCTION}

Germ cell formation is an integral part of sexual reproduction as well as certain types of asexual reproduction as germ cells are a totipotent stem cell line in which meiosis occurs. In many metazoan species, germ cell formation requires a specialized cytoplasm. In Drosophila, this cytoplasm, referred to as germ plasm or pole plasm, contains electron dense organelles called polar granules. Many of the proteins and mRNAs needed for germ cell formation accumulate on or in these structures. Although mammals do not appear to rely on a specialized maternally deposited cytoplasm for germ cell development, many mRNAs and proteins found in the Drosophila germ plasm are conserved in sequence and function in mammalian species. The following discussion focuses on one specific polar granule component, TUD and its novel protein domains (Tudor domains).

\section{GERM PLASM}

Early embryonic development in many different species depends on properly localized maternally deposited factors.

\footnotetext{
*Correspondence: Paul LASKO

Tel: +1 5143986401 Fax: +1 5143985069

E-mail: paul.lasko@mcgill.ca
}

Over 100 years ago, it was first observed that germ cells form from cytoplasm at the posterior of the fertilized egg [1]. This posterior cytoplasm is composed of maternal gene products, is morphologically distinct, and is essential for germ cell formation. In early experiments in beetles, physical disruption or removal of the germ plasm abolished germ cell formation [2]. Similarly, later experiments in Drosophila showed that UV-irradiation of the germ plasm produces adult flies that lack germ cells [3]. However, when germ plasm from non-UV-irradiated embryos was transplanted into UV-irradiated embryos, germ cell formation was rescued [4]. Interestingly, the production of germ cells can be induced if germ plasm is injected into embryos at ectopic sites [5]. Furthermore, these ectopic germ cells could complete germ cell formation when transplanted to the posterior of a host embryo [6]. Taken together the data from these studies indicate that germ plasm is not only essential but is sufficient for germ cell formation. Ultrastructural analysis of Drosophila germ plasm shows that it contains electron dense structures referred to as polar granules, and similar electron dense structures are found in the germ plasm or germ line of other species.

To identify genes required maternally for germ cell specification, screens for grandchildless mutations, that is, maternal-effect sterile mutations, were conducted [reviewed in 7]. Subsequent maternal-effect lethal screens 


\section{Tudor and its domains}

brought about a huge leap in the understanding of germ plasm assembly and germ cell formation, as they uncovered a novel class of genes known as posterior group genes. Mutations of these genes disrupt posterior somatic patterning, as seen by the loss of one or more abdominal segments, which usually results in maternal effect lethality. Mutations in one posterior group gene, nanos (nos), do not initially disrupt germ cell formation but result in a strong posterior group phenotype [8]. When nos mRNA is injected into the posterior of posterior group mutant embryos, posterior segmentation is restored. It was also found that when nos mRNA is injected at the anterior, it can direct posterior patterning at the site of injection [9]. Not only does this show that NOS is the posterior determinant, but also that other posterior group genes are needed for the proper localization of NOS. To support this observation, mutations in other posterior group genes were found to affect NOS protein accumulation, often by abrogation of nos RNA localization $[8,10]$.

Not surprisingly, many posterior group genes encode germ plasm components. These genes have been extensively studied to get a better idea of how they interact at both the genetic and molecular levels to drive germ plasm assembly and germ cell formation. Germ plasm components are deposited into the oocyte during oogenesis, [for a review of oogenesis see 11]. Drosophila oogenesis begins with the asymmetrical division of a germ line stem cell. This division gives rise to a germ line stem cell and a daughter cystoblast. The cystoblast goes through 4 mitotic divisions with incomplete cytokinesis, thus forming a 16cell interconnected germ cell cyst. 15 of these cells become nurse cells while one becomes the oocyte. Nurse cells supply the growing oocyte with the bulk of the RNAs and proteins needed for early embryonic development, including those destined for the germ plasm.

Assembly of the germ plasm during oogenesis occurs in a stepwise fashion where each molecule depends on the localization of the preceding molecules. oskar (osk) mRNA is at the top of this pathway, and mislocalization of osk mRNA to the anterior is capable of inducing germ cell formation at the anterior [12]. Two genes encoding downstream pole plasm components, tud and vasa (vas), are required in addition to osk for pole cell formation at any location, while other posterior-group genes are dispensable for germ cell formation at an ectopic site [12]. This suggested direct roles for $t u d$ and vas in germ cell formation (Fig. 1).

vas encodes a DEAD-box RNA helicase with similarities to eIF4A, which suggests that VAS has a role in regulating translation [14-16]. Ovaries of homozygous vas-null females rarely complete oogenesis and exhibit pleiotropic phenotypes, suggesting that VAS is involved

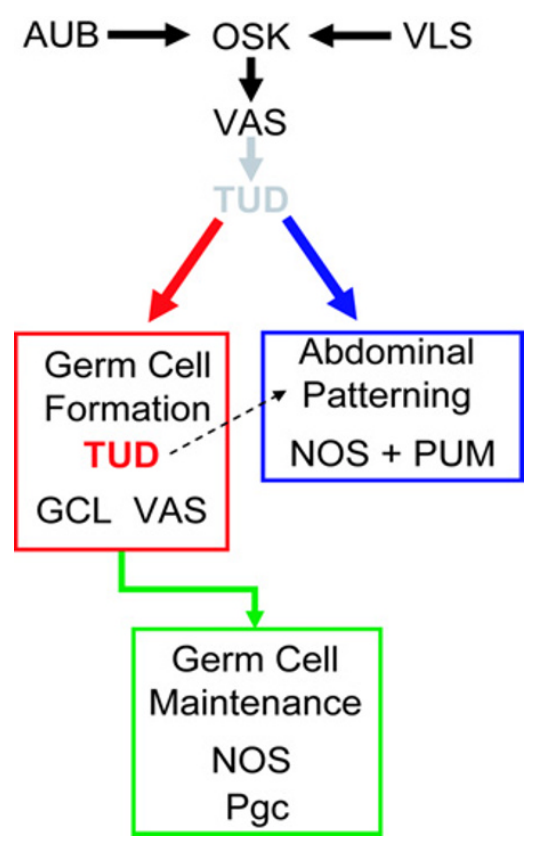

Fig. 1 Pole plasm assembly in brief. "TUD" in grey represents the position originally assigned to TUD in the pole plasm pathway, as initial mutations of tud affected both germ cell and abdomen formation. Recent isolation of a null allele shows that TUD is absolutely needed for germ cell formation, as indicated by the red "TUD". As implied by the dashed arrow TUD does have a role in abdominal patterning but is redundant or not absolutely required as normal abdominal patterning can occur in embryos completely lacking TUD. Thus TUD is the earliest gene absolutely needed for germ cell formation but dispensable for other somatic functions. Valois (VLS) is a cofactor needed for proper OSK accumulation in the germ plasm [13]. Some germ plasm components have roles in multiple functions of the germ plasm as shown with NOS and VAS.

in several earlier processes in oogenesis in addition to its role in the pole plasm [17]. Yeast two hybrid studies show that VAS and OSK bind directly to each other. The interaction of these two proteins plays an integral role in germ cell formation and polar granule assembly, and OSK appears to mediate accumulation of VAS in the germ plasm [18]. Although the localization of VAS does not rely on its ability to bind RNA via the DEAD box RNA helicase, germ cell formation does [19]. More recent work revealed that VAS binds the translation initiation factor eIF5B [20]. A mutated form of VAS-GFP whose eIF5B binding activity has been greatly reduced has been used to study the functional significance of the VAS-eIF5B interaction [21]. This mutated form of VAS-GFP localizes normally, and progeny of females expressing it in a vas mutant genetic background often have normal posterior somatic patterning and are viable. However, germ cell formation is not rescued by this form of VAS, implying 
that the interaction between VAS and a general translation initiation factor is essential for germ cell formation.

It is important to identify RNAs that are essential for germ cell specification and that depend on VAS for activation of translation initiation yet none have been found to date. Two maternally-expressed genes, $g c l$ and $p g c$, encode RNAs that accumulate in the pole plasm downstream of VAS and are specifically required for germ cell specification. $\mathrm{gcl}$ may be involved in establishing or maintaining transcriptional quiescence, an essential feature of primordial germ cells [21]. In the syncytial Drosophila embryo, the first nuclei that migrate to the posterior are destined to become germ cells and become transcriptionally silent. In $g c l$-null embryos these nuclei are transcriptionally active and do not form germ cells. GCL localizes to the nucleoplasmic surface of the nuclear membrane where it is postulated that it might interact with chromosomes directly to inhibit transcription similar to telomeric silencing in yeast.

pgc RNA localizes to polar granules. In flies that express a $p g c$ antisense construct, germ cells form normally and in near-normal numbers, but many do not survive migration to the somatic gonad [22]. Germ cells lacking $p g c$ exhibit precocious expression of somatic markers presumably due to the presence of active, phosphorylated RNApolII [23]. In wild-type germ cells, RNApolII is not normally phosphorylated and phosphorylation, specifically at the carboxy-terminal domain, is needed for RNApolII activity. It is unclear at this time how the reduction of $p g c$ activity represses RNApolII activity at this time [24].

While much has been learned about the composition of the pole plasm, undoubtedly more germ plasm components remain to be identified. Also, many somatically required genes also have germline specific functions. While these genes can sometimes be identified through phenotype-based screens that focus on the germline or by creating germline mutant clones [25], if a mutation blocks oogenesis at an early stage or is cell-lethal then any later function in oocyte patterning will not be uncovered. Biochemical approaches and direct protein interaction screens, such as the two-hybrid screen which identified a role for eIF5B in germ cell formation, will allow identification of somatic genes required for germ cell formation $[20,26,27]$.

\section{TUDOR HAS A KEY ROLE IN GERM CELL ESTABLISHMENT}

tud was one of the first posterior-group genes identified in Drosophila melanogaster, and some alleles give a completely penetrant grandchildless phenotype [28]. Embryos produced by tud mothers have substantially fewer polar granules than do wild-type embryos. Some germ cells form in the progeny of less severe tud mutants, and while these have more polar granule material only a small portion is taken into the newly formed germ cells, which although functional are not morphologically normal. Thus mutations in tud point to a potential correlation between polar granule formation and germ cell formation.

tud encodes a large mRNA of approximately $8 \mathrm{~kb}$ [29] that encodes a large peptide of 2515 amino acids or 285 $\mathrm{kD}$. Over half of TUD is comprised of 11 copies of a novel protein motif called the Tudor domain [30]. tud begins to be expressed very early in oogenesis. tud mRNA localizes to the newly formed oocyte where it accumulates in the posterior and later dissipates. At the same time, tud mRNA is abundant in nurse cells. In later stages of oogenesis and early stages of embryogenesis tud mRNA is uniformly distributed in germ line cells. TUD protein is concentrated around the nurse cell nuclei and in the oocyte in the early stages of oogenesis. The perinuclear localization of TUD is similar to that of VAS, a protein encoded by another posterior group gene. These proteins accumulate in what is called the nuage, an electron dense structure around nurse cell nuclei. TUD protein later accumulates in the posterior of the developing oocyte where it stays until after germ cell formation [31], after which time it can no longer be detected. TUD is also found throughout the early embryo in ring-like structures in the anterior.

A null allele of $t u d$ was recently isolated [32]. As homozygous $t u d$-null individuals allele are fully viable and do not exhibit any defects except those attributable to the pole plasm [32], tud does not have an essential somatic function. Unlike osk and vas [19,36], the tud-null mutation did not affect oogenesis. Surprisingly, some embryos from homozygous tud-null mothers grew to adulthood [32]. Although all tud-null embryos could not form germ cells, approximately $15 \%$ had normal posterior patterning. In tud-null oocytes, posterior localization of OSK and VAS occurs normally. However, the localization of OSK, VAS and NOS is not maintained in embryos produced by tud-null mothers after the developmental stage when pole cells would normally form. This phenomenon was first observed in Drosophila germ plasm formation almost 2 decades ago $[16,33]$. If germ cells do not form due to a mutation affecting a downstream member of the pole plasm assembly pathway, posterior localization of the upstream factors, while initially unaffected, is not maintained. It is unknown if this is an active process where the soma degrades germ plasm components, or a passive process where the germ cells provide an essential structure to store and protect the germ plasm. The $t u d$-null mutant showed that TUD, unlike many other pole plasm components, is required spe- 
cifically for germ cell formation. Thus isolation of a tudnull mutant has begun to unravel two entangled pathways, germ cell formation and abdominal patterning.

\section{A BRIEF ANALYSIS OF TUDOR DOMAINS}

The Tudor domain was first discovered during a comparison of protein sequences, which was done to find homologous regions with sequence or structural similarities $[30,34]$. Several of the first Tudor domain containing proteins that were identified have well known RNA binding motifs. Based on this knowledge, it was suggested that Tudor domains may have a role in RNA metabolism [30]. However, a more complete database analysis of proteins with Tudor domains does not show an association between them and RNA binding motifs. Moreover, recent experimental evidence does not support an RNA-binding function for the Tudor domain. For example, the Drosophila OVARIAN TUMOR (OTU) protein contains a single Tudor domain and is associated with mRNPs, but deletion of its Tudor domain did not disrupt its ability to associate with mRNPs [35].

The mammalian SURVIVAL MOTOR NEURON (SMN) protein also contains a single Tudor domain, and mutations in the corresponding gene are responsible for autosomal recessive proximal spinal muscular atrophy (SMA) [36]. Structural analysis of the SMN Tudor domain shows that it is essentially a "barrel", closed on one end with hydrophobic residues pointing inwards, which is not consistent with an RNA binding function [37, 38] (Fig. 2). Tudor domains have highly conserved amino acids and predicted structure, which suggests that the structure of the Tudor domain in SMN is likely to be very similar to those found in other Tudor domain containing proteins. SMN binds to two SM proteins, SmD1 and SmD3, at their carboxy-terminal ends, which are arginine- and glycine-rich domains [39]. Methylation of the carboxy-terminal ends of SmD1 and SmD3 enhances the binding ability of SMN by several folds. SMN binding is also enhanced when other SMN targets are methylated, [40, 41], particularly when binding partners have symmetrical dimethylation of the arginines (sDMA). SMN cannot efficiently bind unmethylated or asymmetrically methylated carboxyl-terminal ends of SmD1 and SmD3. A single amino acid mutation of the SMN Tudor domain completely inhibits the ability of SMN to bind the SDMAs of SmD1 and SmD3, strongly suggesting that the Tudor domain of SMN is needed for binding to methylated $\mathrm{SmD} 1$ and SmD3 [41].

There are some experimental caveats that may make the conclusion that the Tudor domain is a methylated protein binding domain somewhat premature. First, most of the expression assays were not carried out with full length
SMN constructs. Second, SMN binding was tested against only a small portion of SmD1 and SmD3. Third, SMN lacking portions of its Tudor domain can weakly bind SmD1 and SmD3. Finally, the biological effects of disrupting the SMN Tudor domain-SM protein interactions have not yet been tested. In fact, one study has suggested that deletion of the Tudor domain of SMN is not lethal to the chicken pre-B cell line DT40, while full length SMN is needed for viability of this same cell line [42]. Analysis of human type I SMA patients leads to a different conclusion, however. While $90 \%$ of SMA patients have large deletions of the smn gene, and are therefore not informative as to specific Tudor domain function [43], some SMA patients have missense mutations leading to amino acid changes in conserved residues in Tudor domains $[43,44]$. Therefore, although in a specific cell line the Tudor domain of SMN may not be required for viability, the Tudor domain of SMN is functionally relevant in vivo. It should be noted that type I SMA is a lethal disorder, and individuals with single amino acid changes in Tudor domains still show lethality as early as those with large deletions of the $s m n$ gene.

Recent work with 53BP1 and its role in DNA doublestranded breaks (DSBs) has resolved the issue of Tudor domain functionality [45]. 53BP1 is a conserved checkpoint gene that has been implicated as a sensor for DNA DSBs. Recruitment of 53BP1 to DSBs is crucial for their repair. 53BP1 contains two Tudor domains and mutations specifically in residues predicted to be crucial to proper Tudor domain folding inhibit the recruitment of 53BP1 to DNA DSBs. 53BP1 was found to bind to histone $\mathrm{H} 3$ directly. $\mathrm{H} 3$ had to be methylated for this interaction, specifically at Lys 79. The removal of the methyltransferase (DOT1L) necessary for methylating Lys 79 had the same effect as disrupting the Tudor domains of 53BP1. Mutating the Tudor domains of 53BP1 or inhibiting the methylation of Lys 79 of H3 had the same effect as these cells were not able to respond to DNA DSBs. This evidence makes it clear that Tudor domains do not have a role in RNA metabolism but instead bind to methylated amino acids. It will be interesting to see if variations in Tudor domains determine what type of methylated amino acids they bind, either lysines or arginines, and if the lysines are symmetrically methylated as were the arginines in SmD1 and SmD3.

\section{POLAR GRANULES: A MYSTERY WRAPPED IN PROKARYOTIC TRANSLATION?}

The germ plasm of Drosophila was first observed using light microscopy over 100 years ago. It is morphologically distinct due to the presence of large electron dense structures called polar granules, which are associated with mitochondria. Polar granules are large mRNP aggregates 

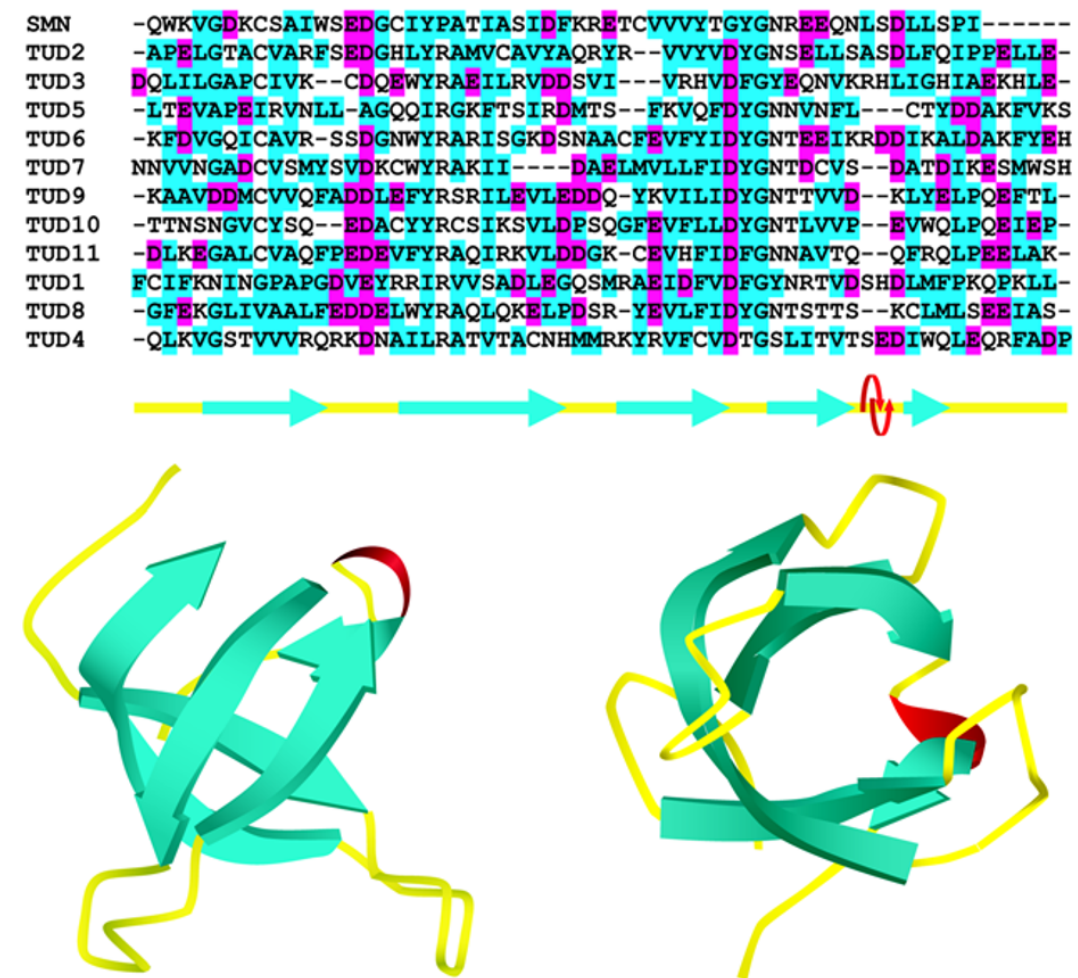

Fig. 2 The Tudor Domain. (A) Amino acid sequence of the Tudor domain in SMN (Homo sapiens) in comparison to the 11 Tudor domains of TUD. Hydrophobic residues are highlighted in blue and negativelycharged residues are highlighted in pink. Although there is a conservation of residues of Tudor domains across species, what is more conserved are the locations of hydrophobic and negative amino acids. (B) In spite of the many amino acid differences between the Tudor domains even in the same protein (as shown in A) the predicted secondary structures are very similar to that shown in B. $\alpha$ sheets are represented in blue and red arrows show the position of the $\alpha$-helix. (C) Front view of the Tudor fold as determined by NMR. (D) Bottom view of the Tudor domain showing it to be tube, the $\mathrm{N}$-terminal end of the Tudor domain is predicted to fold over the top end making the Tudor domain are barrel like structures with a closed end (angle not shown). Modified from Selenko et al [37], see for a detailed explanation of the Tudor domain structure. that resemble electron dense aggregates seen in the germline of other species. Polar granules are dynamic structures that change in size, shape and presumably composition throughout oogenesis and early embryogenesis [46-49]. Many components of the Drosophila polar granule can be found in the nuage, a perinuclear structure in ovarian nurse cells. These include VAS, TUD, and Aubergine (AUB), a translational regulator of $o s k$ mRNA $[50,51]$. The fact that nuage and polar granules share some components suggests that the former might be a precursor form of the latter. However, real-time analysis of GFP-VAS and GFPAUB localization suggests that the nuage may disassemble before localization to the posterior, and polar granules assemble de novo [51]. It will be interesting to see if this observation can be reconfirmed using electron microscopy.

Shortly after fertilization, polar granules lose a considerable amount of electron density due to a loss of RNA from the polar granules [52]. It is unknown if the RNAs are translated and degraded or dispersed into the newly forming germ cells. What remains of the polar granules are transported by aggregation onto the centrosomes into the newly forming germ cells [49, 53]. Many germ plasm components localize to polar granules as determined by electron microscopy (Tab. 1). The functional significance of the polar granule structure itself remains an open question, and the dynamics of the polar granules, nuage and other electron dense structures in the germline must be re-examined as the original ultrastructural analysis was done prior to the identification of several polar granule components.

\section{MITOCHONDRIAL RRNA AND GERM CELL SPECIFICATION}

As discussed above, UV-irradiation of the pole plasm of Drosophila disrupts germ cell formation. This effect can be rescued by injection of mitochondrial large rRNA (mtlrRNA) into the irradiated pole plasm [68]. A strong case can be made that mtrRNA is needed for germ cell formation, as ribozyme-mediated depletion of mtlrRNA results in a severe reduction of the number of pole cells formed [69]. Ultrastructural analysis of mtrRNA in the pole plasm shows that mtlrRNA localizes to the polar granules along with small mitochondrial rRNA (mtsrRNA) and mitochondrial ribosomal proteins $\mathrm{S} 12$ and L7/L12 [59, 60]. Electron microscopy revealed that the mtrRNAs and mitochondrial ribosomal proteins aggregate together to form mitochondrial ribosomes on the periphery of the polar granule (Fig. 3).

Are mitochondrial tRNAs and other factors involved in mitochondrial translation somehow used by polar granule ribosomes? If so, then mRNAs translated on the polar granules would be produced with mitochondrial codon usage, 
Tab. 1 Known or suspected polar granule components. Relatively few polar granule components have been identified, and many that are suspected to be polar granule components have not been confirmed by electron microscopy. "EM data" indicates if a component has been shown to localize to the polar granules using electron microscopy.

\begin{tabular}{|c|c|c|c|}
\hline Component & Description & $\begin{array}{c}\text { EM } \\
\text { DATA }\end{array}$ & Other data \\
\hline Oskar & Unknown function & YES & $\begin{array}{l}\text { Crucial and sufficient for germ cell formation and } \\
\text { abdominal patterning }[12,54,55] . \\
\text { Needed for polar granule formation [18]. }\end{array}$ \\
\hline Vasa & DEAD-BOX RNA helicase & YES & $\begin{array}{l}\text { Role in translational activation needed for germ cell } \\
\text { formation }[20,26] \text {. } \\
\text { Needed for polar granule formation }[14-16,56]\end{array}$ \\
\hline Tudor & $\begin{array}{l}\text { Unknown, needed for germ } \\
\text { cell formation. }\end{array}$ & YES & $\begin{array}{l}\text { Localizes to polar granules and mitochondria in the germ } \\
\text { plasm and fibers that connect the two [57]. } \\
\text { May have a role in transporting mtrRNAs from } \\
\text { mitochondria to polar granules [57]. } \\
\text { Needed for polar granule formation [28, 32]. }\end{array}$ \\
\hline Staufen & RNA binding protein & YES & $\begin{array}{l}\text { Needed for proper OSK localization [58]. } \\
\text { Needed for polar granule formation [18]. }\end{array}$ \\
\hline mtlrRNA & $\begin{array}{l}\text { Mitochondrially encoded large } \\
\text { rRNA subunit }\end{array}$ & YES & $\begin{array}{l}\text { Forms a mitochondrial ribosome on the surface of polar } \\
\text { granules }[59,60] .\end{array}$ \\
\hline mtsrRNA & $\begin{array}{l}\text { Mitochondrially encoded } \\
\text { small rRNA subunit }\end{array}$ & YES & $\begin{array}{l}\text { Forms a mitochondrial ribosome on the surface of polar } \\
\text { granules }[60,61] \text {. }\end{array}$ \\
\hline $\begin{array}{l}\text { Mitochondrial } \\
\text { Ribosomal Protein } \\
\text { S12 }\end{array}$ & $\begin{array}{l}\text { Mitochondrially encoded } \\
\text { ribosomal protein }\end{array}$ & YES & $\begin{array}{l}\text { Forms a mitochondrial ribosome on the surface of polar } \\
\text { granules [60]. }\end{array}$ \\
\hline $\begin{array}{l}\text { Mitochondrial } \\
\text { Ribosomal Protein } \\
\text { L7/L12 }\end{array}$ & $\begin{array}{l}\text { Mitochondrially encoded } \\
\text { ribosomal protein }\end{array}$ & YES & $\begin{array}{l}\text { Forms a mitochondrial ribosome on the surface of polar } \\
\text { granules [60]. }\end{array}$ \\
\hline $\begin{array}{l}\text { Polar granule } \\
\text { component }\end{array}$ & Non-coding RNA & YES & $\begin{array}{l}\text { Involved in transcriptional quiescence after germ cell } \\
\text { formation }[22,23] \text {. }\end{array}$ \\
\hline Fat Facets & $\begin{array}{l}\text { Deubiquitinating enzyme } \\
\text { (DUB) }\end{array}$ & NO & $\begin{array}{l}\text { Enrichment of FAF mRNA to the posterior of early } \\
\text { embryos, and FAF binds to VAS directly, suggesting that } \\
\text { at least a portion is on the polar granules with VAS [ } 27 \text {, } \\
62] \text {. }\end{array}$ \\
\hline Aubergine & $\begin{array}{l}\text { Similar to eIF } 2 \mathrm{C}, \mathrm{RNAi} \\
\text { machinery component. }\end{array}$ & NO & $\begin{array}{l}\text { AUB-GFP colocalizes to the germ plasm in a punctuate } \\
\text { pattern with other GFP labeled polar granule components } \\
\text { [63]. }\end{array}$ \\
\hline cyclin B mRNA & Cell cycle regulator. & NO & $\begin{array}{l}\text { Punctate mRNA localization to posterior [64]. } \\
\text { Recently shown to have a specific role in the Drosophila } \\
\text { germline [65]. }\end{array}$ \\
\hline hsp83 mRNA & Chaperone protein & NO & Localization to posterior as determined RNA in situ [66]. \\
\hline gcl mRNA & $\begin{array}{l}\text { GCL is needed to maintain } \\
\text { germ plasm transcriptional } \\
\text { quiescence. }\end{array}$ & NO & $\begin{array}{l}\text { Localization of gcl mRNA to the posterior in a granular } \\
\text { fashion [67]. }\end{array}$ \\
\hline P95 & UNKNOWN & N.A. & $\begin{array}{l}\text { Unknown protein isolated in biochemical purification of } \\
\text { polar granules [7]. }\end{array}$ \\
\hline
\end{tabular}




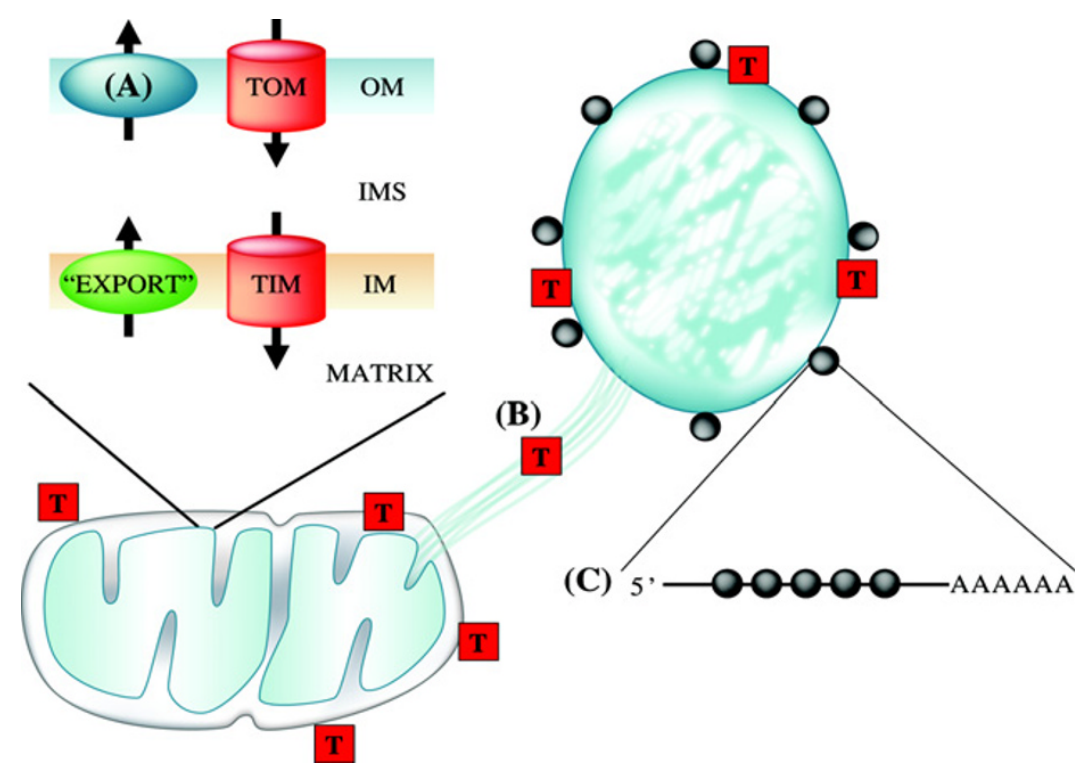

Fig. 3 Transport of mtrRNA to polar granules. (A) The TOM and TIM complexes are well studied complexes involved in transport into the mitochondria; the "Export" complex is a partially understood complex that moves molecules across the inner membrane. Very little is known about how molecules can be transported across the outer membrane or out of the mitochondria altogether. (B) It has been observed that thin fibers connect the polar granules and mitochondria. TUD localizes to these fibers, along with mtrRNAs, suggesting it is a mitochondria to polar granule transport structure. What comprises these fibers and how they function is unknown. (C) Mitochondrial polysomes localize to the periphery of polar granules, but which mRNAs are translated in these complexes is unknown. Red squares with a "T' represent TUD.

and one class of stop codon (UGA) would be read through. It may also be that mitochondrial translation is needed to overcome some form of translational repression in the germ plasm or to ensure that somatic genes are not translated in the germ plasm. Whatever their significance, the formation of mitochondrial ribosomes in the germ plasm is highly conserved in animal evolution. Mitochondrially-derived ribosomes also form on germinal granules, structures very similar to polar granules, that are present in Xenopus germ plasm $[70,71]$. Recently, 16S rRNA was found outside the mitochondria in human testis, localized to the nuclei of spermatogenic cells, which suggests that mitochondrial ribosomes may have a function in the mammalian germline [72].

This leads to another interesting question: how are macromolecules such as mtrRNAs transported out of the mitochondria? The transport of macromolecules into the mitochondria via the TOM and TIM complexes is well understood [reviewed in 73]. However, the export of proteins from the inner matrix across the inner membrane is less well understood, and how macromolecules completely leave the mitochondria is still a mystery. The bidirectional mitochondrial transport of spermine, a polyamine involved in several biological processes, is one of the few examples of how molecules are transported out of the mitochondria.
The transport of spermine is facilitated by high mitochondrial membrane potential and $\mathrm{pH}$ gradient [74]. It has been reported that the membrane potential of the mitochondria in the germ plasm is increased in the early embryo, as seen with rhodamine 123 staining [75]. However, the membrane potential of Drosophila germ plasm mitochondria is not affected by UV-irradiation. The injection of mtlrRNA into UV-irradiated embryos rescues germ cell formation, suggesting that mtrRNAs are not transported out of the mitochondria even with high membrane potential. This implies that high membrane potential is not a prerequisite for transport out of the mitochondria. It is possible that UV-irradiated embryos still transport mtrRNA out of the mitochondria and it is then deactivated or that UV-irradiation does affect transport of mtrRNA at a point downstream of high membrane potential. Reducing mitochondrial membrane potential in the posterior pole plasm using commercially available anti-cancer drugs could be very illuminating if it could be demonstrated that no mitochondrially encoded rRNAs or proteins are seen on the polar granules after treatment. Finding out if high membrane potential is needed for transport out of the mitochondria is a great first step but more work is clearly needed to determine how macromolecules are transported out of the mitochondria. 


\section{NOW THAT THE MTRNA IS OUT OF THE MITOCHONDRIA...WHAT NEXT?}

Like other pole plasm components such as OSK and VAS, TUD localizes to the polar granules. A unique and interesting characteristic of the TUD distribution in the pole plasm is that TUD also localizes to the mitochondria, not just the polar granules [31, 57]. Closer examination shows that TUD localizes with mtrRNAs to the fibrous material that seems to connect polar granules and mitochondria. Although mutations in vas, osk and tud all lead to a loss of mtrRNA in the pole plasm, the observation that TUD localizes to the mitochondria and polar granules led to speculation that TUD may have a role in mtrRNA transport to the polar granules. In fact, in embryos produced by $t u d$ mutants mtrRNAs are not transported from the mitochondria to the polar granules. Do these embryos simply lack polar granules for mtrRNA localization or do they lose the ability to transport mtrRNAs to polar granules? To distinguish these possibilities, the localization of mtrRNAs was compared to the localization of VAS. In a tud mutant that still made polar granules, albeit at a greatly reduced quantity, VAS still localized to these reduced polar granules. However, no mtrRNAs localized to these polar granules, suggesting a direct role for TUD in mtlrRNA localization. However, it can still be argued that this result stems from a failure of the abnormal polar granules in tud mutants to receive or capture mtrRNAs, rather than a defect in mtrRNA transport.

\section{CONSERVATION OF DROSOPHILA GERM CELL FORMATION GENES IN MAMMALS AND OTHER SPECIES}

A wide variety of species relies on a germ plasm for germ cell formation, and germ plasm generally contains polar granule like structures [76]. During germ cell migration, in both mammals and Drosophila, there is a great deal of conservation of genes and gene function [reviewed in 77, 78]. The following discussion will focus on mammalian orthologues of some Drosophila germ plasm genes. The most notable example is vas. Many species appear to have one or more vas homologs whose products are expressed in germline cells [76, 79-84]. These vas homologs are essential for germ line development in many of these species $[15,16,19,82,85-86]$. The MVH (mouse vasa homolog) protein localizes to mammalian germ cells very early in development, and later localizes to the spermatogonia, where it is associated with the chromatoid body. The chromatoid body is a large electron dense structure located near the spermatogenic cell nucleus and is associated with mitochondria, thus in several aspects it resembles the polar granule. Mice lacking $m v h$ function do not complete spermatogenesis. It is unknown at this time whether MVH associates with eIF5B.

Other mouse homologs of Drosophila germ plasm genes also function in germ line development. Mouse germ cell-less ( $m g c l-1)$ localizes to the germline, and like $m v h$, $m g c l-1$ is needed for spermatogenesis but not for oogenesis [87]. mGCL-1 protein localizes to testicular cells and, as for GCL, a large amount of this protein localizes to the nuclear envelope. However not all mGCL-1 localizes to the nuclear envelope, a significant portion is seen in the nuclei surrounding DNA [88]. The expression of mGCL-1 in flies that are null for Drosophila gcl rescues germ cell formation, which suggests that not only is there sequence similarity but a conservation of function as well [89].

The Xenopus protein XTR (Xenopus Tudor Repeats) [90] and a murine protein MTR (Mouse Tudor Repeats) (MTR) [91] may be functional counterparts of TUD, as both are expressed in germ line cells. XTR was first thought to contain four Tudor domains and one short Tudor domain located at its N-terminal end, which probably cannot form a Tudor fold. However, recent protein database searches suggest that there may be as many as 7 complete Tudor repeats in XTR [92]. Although TUD, MTR and XTR have significant sequence similarity, it is premature to consider them as orthologs until more functional information is available for the vertebrate proteins. However, MTR localizes to the chromatoid bodies in the mammalian male germ line, and when expressed in cell culture, MTR is able to induce the formation of chromatoid-like bodies [91]. Based on these observations, it would not be surprising if mtr null mice, when generated, will be found to be compromised with regard to male fertility.

Given its position at the top of the Drosophila pole plasm hierarchy, it is perhaps surprising that osk is not widely conserved in evolution. Perhaps its function is unique to flies; for example, VAS and other downstream components may specifically require OSK to be anchored in the pole plasm in that organism. While osk recruits all downstream pole plasm components, it is not actually certain that it is required itself for germ cell specification, as for technical reasons it has not yet been possible to mis-localize VAS and/or TUD to an ectopic site such as the anterior pole of the embryo without also mislocalizing osk. It could also be that in other species, the molecular function of OSK is carried out by another gene or set of genes.

In Drosophila, germ cell formation is integrally connected to patterning of the posterior soma. Many other species, even those that localize maternally deposited factors to a germ plasm, do not share this characteristic. Consistent with this, the functions of some germ plasm components have diverged over evolutionary time. An example is NOS, which is highly conserved both in sequence 
and function in mammals. As mentioned NOS is required for posterior somatic patterning in Drosophila. It is not required for initial germ cell specification, but it is critical for germ cell function as it is involved in establishing and maintaining transcriptional quiescence. In mouse, at least two nos homologs are expressed in the germline, nos 2 and nos 3 [93]. Mutation of nos 2 blocks spermatogenesis, and mice lacking nos 3 are blocked both for spermatogenesis and oogenesis. Similar to NOS in Drosophila, homologs in mice are not needed for the initial formation of germ cells but are required for the maintenance of germ cell fate. In mice, NOS1 binds the mouse PUMILIO homolog just as NOS binds PUMILIO in Drosophila, suggesting a conservation of molecular function [94]. However, unlike in Drosophila there does not seem to be a role for mouse NOS2 or NOS3 in somatic patterning.

\section{FINAL REMARKS}

Although mammals and Drosophila diverged over 400 million years ago and their embryonic development is very dissimilar, there is remarkable conservation of Drosophila genes encoding germ plasm components. However, the functions of these genes in germ line development have somewhat diverged. Most notably, while in Drosophila $v a s, t u d$ and $g c l$ are required during oogenesis for embryonic patterning and for germ cell specification, in mammals their possible counterparts appear to be essential only in spermatogenesis. This may imply that mammalian spermatogenesis employs more evolutionarily ancient mechanisms that are also used for maternal specification of germ cells in Drosophila, and that mammalian oogenesis is a more recently diverged developmental pathway.

\section{ACKNOWLEDGMENTS}

We are grateful to Jean-Paul Acco for figure preparation.

\section{REFERENCES}

1 Weismann A Continuity of the Germ Plasm. In: Poulton E et al, Eds. Essays upon heredity and kindred biological problems: Clarendon Press, Oxford 1885.

2 Hegner RW. The effects of removing the germ cell determinants from the eggs of some chrysomelid beetles. Biol Bull 1908; 16: 19.

3 Geigy R. Action de l'ultra-violet sûr le pôle germinale dans l'ouef de Drosophila melanogaster. Rev Suisse Zool 1931; 38:187288.

4 Okada M, Kleinman IA, Schneiderman HA. Restoration of fertility in sterilized Drosophila eggs by transplantation of polar cytoplasm. Dev Biol 1974; 37:43-54.

5 Illmensee K, Mahowald AP. Transplantation of posterior polar plasm in Drosophila. Induction of germ cells at the anterior pole of the egg. Proc Natl Acad Sci U S A 1974; 71:1016-20.

6 Illmensee K, Mahowald AP. The autonomous function of germ plasm in a somatic region of the Drosophila egg. Exp Cell Res 1976; 97:127-40.

7 Mahowald AP. Assembly of the Drosophila germ plasm. Int Rev Cytol 2001; 203:187-213.

8 Lehmann R, Nusslein-Volhard C. The maternal gene nanos has a central role in posterior pattern formation of the Drosophila embryo. Development 1991; 112:679-91.

9 Wang C, Lehmann R. Nanos is the localized posterior determinant in Drosophila. Cell 1991; 66:637-47.

10 Wang C, Dickinson LK, Lehmann R. Genetics of nanos localization in Drosophila. Dev Dyn 1994; 199:103-15.

11 Spradling AC (1993) Developmental genetics of oogenesis. Cold Spring Harbor Laboratory Press, Cold Spring Harbor, NY.

12 Ephrussi A, Lehmann R. Induction of germ cell formation by oskar. Nature 1992; 358:387-92.

13 Cavey M, Hijal S, Zhang X, Suter B. Drosophila valois encodes a divergent WD protein that is required for Vasa localization and Oskar protein accumulation. Development 2005; 132:459-68.

14 Hay B, Jan LY, Jan YN. A protein component of Drosophila polar granules is encoded by vasa and has extensive sequence similarity to ATP-dependent helicases. Cell 1988; 55:577-87.

15 Lasko PF, Ashburner M. The product of the Drosophila gene vasa is very similar to eukaryotic initiation factor-4A. Nature 1988; 335:611-7.

16 Lasko PF, Ashburner M. Posterior localization of vasa protein correlates with, but is not sufficient for, pole cell development. Genes Dev 1990; 4:905-21.

17 Styhler S, Nakamura A, Swan A, Suter B, Lasko P. vasa is required for GURKEN accumulation in the oocyte, and is involved in oocyte differentiation and germline cyst development. Development 1998; 125:1569-78.

18 Breitwieser W, Markussen FH, Horstmann H, Ephrussi A. Oskar protein interaction with Vasa represents an essential step in polar granule assembly. Genes Dev 1996; 10:2179-88.

19 Liang L, Diehl-Jones W, Lasko P. Localization of vasa protein to the Drosophila pole plasm is independent of its RNA-binding and helicase activities. Development 1994; 120:1201-11.

20 Carrera P, Johnstone O, Nakamura A, et al. VASA mediates translation through interaction with a Drosophila yIF2 homolog. Mol Cell 2000; 5:181-7.

21 Pirrotta V. Silence in the germ. Cell 2002; 110:661-4.

22 Nakamura A, Amikura R, Mukai M, Kobayashi S, Lasko PF. Requirement for a noncoding RNA in Drosophila polar granules for germ cell establishment. Science 1996; 274:2075-9.

23 Martinho RG, Kunwar PS, Casanova J, Lehmann R. A noncoding RNA is required for the repression of RNApolII-dependent transcription in primordial germ cells. Curr Biol 2004; 14:159-65.

24 Seydoux G, Dunn MA. Transcriptionally repressed germ cells lack a subpopulation of phosphorylated RNA polymerase II in early embryos of Caenorhabditis elegans and Drosophila melanogaster. Development 1997; 124:2191-201.

25 Chou TB, Perrimon N. The autosomal FLP-DFS technique for generating germline mosaics in Drosophila melanogaster. Genetics 1996; 144:1673-9.

26 Johnstone O, Lasko P. Interaction with eIF5B is essential for Vasa function during development. Development 2004; 131:416778.

27 Liu N, Dansereau DA, Lasko P. Fat facets interacts with vasa in the Drosophila pole plasm and protects it from degradation. Curr Biol 2003; 13:1905-9. 
Tudor and its domains

28 Boswell RE, Mahowald AP. tudor, a gene required for assembly of the germ plasm in Drosophila melanogaster. Cell 1985; 43:97104.

29 Golumbeski GS, Bardsley A, Tax F, Boswell RE. tudor, a posterior-group gene of Drosophila melanogaster, encodes a novel protein and an mRNA localized during mid-oogenesis. Genes Dev 1991; 5:2060-70.

30 Ponting CP. Tudor domains in proteins that interact with RNA. Trends Biochem Sci 1997; 22:51-2.

31 Bardsley A, McDonald K, Boswell RE. Distribution of tudor protein in the Drosophila embryo suggests separation of functions based on site of localization. Development 1993; 119:20719.

32 Thomson T, Lasko P. Drosophila tudor is essential for polar granule assembly and pole cell specification, but not for posterior patterning. Genesis 2004; 40:164-70.

33 Iida T, Kobayashi S. Delocalization of polar plasm components caused by grandchildless mutations, gs(1)N26 and gs(1)N441, in Drosophila melanogaster. Dev Growth Differ 2000; 42:5360.

34 Callebaut I, Mornon JP. The human EBNA-2 coactivator p100: multidomain organization and relationship to the staphylococcal nuclease fold and to the tudor protein involved in Drosophila melanogaster development. Biochem J 1997; 321 (Pt 1):125-32.

35 Glenn LE, Searles LL. Distinct domains mediate the early and late functions of the Drosophila ovarian tumor proteins. Mech Dev 2001; 102:181-91.

36 Talbot K, Miguel-Aliaga I, Mohaghegh P, Ponting CP, Davies KE. Characterization of a gene encoding survival motor neuron (SMN)-related protein, a constituent of the spliceosome complex. Hum Mol Genet 1998; 7:2149-56.

37 Sprangers R, Selenko P, Sattler M, Sinning I, Groves MR. Definition of domain boundaries and crystallization of the SMN Tudor domain. Acta Crystallogr D Biol Crystallogr 2003; 59: 366-8.

38 Selenko P, Sprangers R, Stier G, et al. SMN tudor domain structure and its interaction with the Sm proteins. Nat Struct Biol 2001; 8:27-31.

39 Friesen WJ, Dreyfuss G. Specific sequences of the Sm and Smlike (Lsm) proteins mediate their interaction with the spinal muscular atrophy disease gene product (SMN). J Biol Chem 2000; 275:26370-5.

40 Friesen WJ, Massenet S, Paushkin S, Wyce A, Dreyfuss G. SMN, the product of the spinal muscular atrophy gene, binds preferentially to dimethylarginine-containing protein targets. Mol Cell 2001; 7:1111-7.

41. Brahms H, Meheus L, de Brabandere V, Fischer U, Luhrmann R. Symmetrical dimethylation of arginine residues in spliceosomal Sm protein B/B' and the Sm-like protein LSm4, and their interaction with the SMN protein. Rna 2001; 7:1531-42.

42 Wang J, Dreyfuss G. Characterization of functional domains of the SMN protein in vivo. J Biol Chem 2001; 276:45387-93.

43 Cusco I, Barcelo MJ, del Rio E, Baiget M, Tizzano EF. Detection of novel mutations in the SMN Tudor domain in type I SMA patients. Neurology 2004; 63:146-9.

44 Buhler D, Raker V, Luhrmann R, Fischer U. Essential role for the tudor domain of SMN in spliceosomal U snRNP assembly: implications for spinal muscular atrophy. Hum Mol Genet 1999; 8:2351-7.

45 Huyen Y, Zgheib O, Ditullio RA Jr, et al. Methylated lysine 79 of histone $\mathrm{H} 3$ targets 53BP1 to DNA double-strand breaks. Nature 2004; 432:406-11.

46 Mahowald A. Developmental morphology of polar granules Including obervations on pole cell behavior and distribution during embryogenesis. J Morph 1963; 112:129-145.

47 Mahowald AP. Electron microscopy of the formation of the cellular blastoderm in Drosophila melanogaster. Exp Cell Res 1963; 32:457-68.

48 Mahowald AP. Polar granules of Drosophila. 3. The continuity of polar granules during the life cycle of Drosophila. J Exp Zool 1971; 176:329-43.

49 Mahowald AP. Polar granules of Drosophila. II. Ultrastructural changes during early embryogenesis. J Exp Zool 1968; 167:23761.

50 Wilson JE, Connell JE, Macdonald PM. aubergine enhances oskar translation in the Drosophila ovary. Development 1996; 122: 1631-9.

51 Snee MJ, Macdonald PM. Live imaging of nuage and polar granules: evidence against a precursor-product relationship and a novel role for Oskar in stabilization of polar granule components. J Cell Sci 2004; 117:2109-20.

52 Mahowald AP. Polar granules of Drosophila. IV. Cytochemical studies showing loss of RNA from polar granules during early stages of embryogenesis. J Exp Zool 1971; 176:345-52.

53 Mahowald AP. Fine structure of pole cells and polar granules in Drosophila melanogaster. J Exp Zool 1962; 151:201-215.

54 Smith JL, Wilson JE, Macdonald PM. Overexpression of oskar directs ectopic activation of nanos and presumptive pole cell formation in Drosophila embryos. Cell 1992; 70:849-59.

55 Lehmann R, Nusslein-Volhard C. Abdominal segmentation, pole cell formation, and embryonic polarity require the localized activity of oskar, a maternal gene in Drosophila. Cell 1986; 47:14152.

56 Hay B, Ackerman L, Barbel S, Jan LY, Jan YN. Identification of a component of Drosophila polar granules. Development 1988; 103:625-40.

57 Amikura R, Hanyu K, Kashikawa M, Kobayashi S. Tudor protein is essential for the localization of mitochondrial RNAs in polar granules of Drosophila embryos. Mech Dev 2001; 107:97104.

58 St Johnston D, Beuchle D, Nusslein-Volhard C. Staufen, a gene required to localize maternal RNAs in the Drosophila egg. Cell 1991; 66:51-63.

59 Kobayashi S, Amikura R, Okada M. Presence of mitochondrial large ribosomal RNA outside mitochondria in germ plasm of Drosophila melanogaster. Science 1993; 260:1521-4.

60 Amikura R, Kashikawa M, Nakamura A, Kobayashi S. Presence of mitochondria-type ribosomes outside mitochondria in germ plasm of Drosophila embryos. Proc Natl Acad Sci U S A 2001; 98:9133-8.

61 Kashikawa M, Amikura R, Nakamura A, Kobayashi S. Mitochondrial small ribosomal RNA is present on polar granules in early cleavage embryos of Drosophila melanogaster. Dev Growth Differ 1999; 41:495-502.

62 Fischer-Vize JA, Rubin GM, Lehmann R. The fat facets gene is required for Drosophila eye and embryo development. Development 1992; 116:985-1000.

63 Harris AN, Macdonald PM. Aubergine encodes a Drosophila polar granule component required for pole cell formation and related to eIF2C. Development 2001; 128:2823-32. 
64 Raff JW, Whitfield WG, Glover DM. Two distinct mechanisms localise cyclin B transcripts in syncytial Drosophila embryos. Development 1990; 110:1249-61.

65 Wang Z, Lin H. The division of Drosophila germline stem cells and their precursors requires a specific cyclin. Curr Biol 2005; 15:328-33.

66 Ding D, Parkhurst SM, Halsell SR, Lipshitz HD. Dynamic Hsp83 RNA localization during Drosophila oogenesis and embryogenesis. Mol Cell Biol 1993; 13:3773-81.

67 Jongens TA, Hay B, Jan LY, Jan YN. The germ cell-less gene product: a posteriorly localized component necessary for germ cell development in Drosophila. Cell 1992; 70:569-84.

68 Kobayashi S, Okada M. Restoration of pole-cell-forming ability to UV-irradiated Drosophila embryos by injection of mitochondrial lrRNA. Development 1989; 107:733-42.

69 Iida T, Kobayashi S. Essential role of mitochondrially encoded large rRNA for germ-line formation in Drosophila embryos. Proc Natl Acad Sci U S A 1998; 95:11274-8.

70 Kobayashi S, Amikura R, Mukai M. Localization of mitochondrial large ribosomal RNA in germ plasm of Xenopus embryos. Curr Biol 1998; 8:1117-20.

71 Kashikawa M, Amikura R, Kobayashi S. Mitochondrial small ribosomal RNA is a component of germinal granules in Xenopus embryos. Mech Dev 2001; 101:71-7.

72 Villegas J, Araya P, Bustos-Obregon E, Burzio LO. Localization of the 16S mitochondrial rRNA in the nucleus of mammalian spermatogenic cells. Mol Hum Reprod 2002; 8:977-83.

73 Koehler CM. New developments in mitochondrial assembly. Annu Rev Cell Dev Biol 2004; 20:309-35.

74 Siliprandi D, Toninello A, Dalla Via L. Bidirectional transport of spermine in rat liver mitochondria. Biochim Biophys Acta 1992; 1102:62-6.

75 Akiyama T, Okada M. Spatial and developmental changes in the respiratory activity of mitochondria in early Drosophila embryos. Development 1992; 115:1175-82.

76 Tsunekawa N, Naito M, Sakai Y, Nishida T, Noce T. Isolation of chicken vasa homolog gene and tracing the origin of primordial germ cells. Development 2000; 127:2741-50.

77. Saffman EE, Lasko P. Germline development in vertebrates and invertebrates. Cell Mol Life Sci 1999; 55:1141-63.

78 Santos AC, Lehmann R. Germ cell specification and migration in Drosophila and beyond. Curr Biol 2004; 14:R578-89.

79 Fujiwara Y, Komiya T, Kawabata H, et al. Isolation of a DEADfamily protein gene that encodes a murine homolog of Drosophila vasa and its specific expression in germ cell lineage. Proc Natl Acad Sci U S A 1994; 91:12258-62.

80 Ikenishi K, Tanaka TS. Involvement of the protein of Xenopus vasa homolog (Xenopus vasa-like gene 1, XVLG1) in the differentiation of primordial germ cells. Dev Growth Differ 1997; 39: 625-33.
81 Shinomiya A, Tanaka M, Kobayashi T, Nagahama Y, Hamaguchi $\mathrm{S}$. The vasa-like gene, olvas, identifies the migration path of primordial germ cells during embryonic body formation stage in the medaka, Oryzias latipes. Dev Growth Differ 2000; 42:31726.

82 Kuznicki KA, Smith PA, Leung-Chiu WM, et al. Combinatorial RNA interference indicates GLH-4 can compensate for GLH-1; these two $\mathrm{P}$ granule components are critical for fertility in $\mathrm{C}$. elegans. Development 2000; 127:2907-16.

83 Olsen LC, Aasland R, Fjose A. A vasa-like gene in zebrafish identifies putative primordial germ cells. Mech Dev 1997; 66: 95-105.

84 Yoon C, Kawakami K, Hopkins N. Zebrafish vasa homologue RNA is localized to the cleavage planes of 2- and 4-cell-stage embryos and is expressed in the primordial germ cells. Development 1997; 124:3157-65.

85 Tanaka SS, Toyooka Y, Akasu R, et al. The mouse homolog of Drosophila Vasa is required for the development of male germ cells. Genes Dev 2000; 14:841-53.

86 Hay B, Jan LY, Jan YN. Localization of vasa, a component of Drosophila polar granules, in maternal-effect mutants that alter embryonic anteroposterior polarity. Development 1990; 109: 425-33.

87 Kleiman SE, Yogev L, Gal-Yam EN, et al. Reduced human germ cell-less (HGCL) expression in azoospermic men with severe germinal cell impairment. J Androl 2003; 24:670-5.

88 Maekawa M, Ito C, Toyama Y, et al. Stage-specific expression of mouse germ cell-less-1 (mGCL-1), and multiple deformations during mgcl-1 deficient spermatogenesis leading to reduced fertility. Arch Histol Cytol 2004; 67:335-47.

89 Leatherman JL, Kaestner KH, Jongens TA. Identification of a mouse germ cell-less homologue with conserved activity in Drosophila. Mech Dev 2000; 92:145-53.

90 Ikema Y, Hiyoshi M, Daiyasu H, et al. Two novel genes expressed in Xenopus germ line: characteristic features of putative protein structures, their gene expression profiles and their possible roles in gametogenesis and embryogenesis. Mol Reprod Dev 2002; 62:421-30.

91 Chuma S, Hiyoshi M, Yamamoto A, et al. Mouse Tudor Repeat1 (MTR-1) is a novel component of chromatoid bodies/nuages in male germ cells and forms a complex with snRNPs. Mech Dev 2003; 120:979-90.

92 Sigrist CJ, Cerutti L, Hulo N, et al. PROSITE: a documented database using patterns and profiles as motif descriptors. Brief Bioinform 2002; 3:265-74.

93 Tsuda M, Sasaoka Y, Kiso M, et al. Conserved role of nanos proteins in germ cell development. Science 2003; 301:1239-41.

94 Jaruzelska J, Kotecki M, Kusz K, et al. Conservation of a PumilioNanos complex from Drosophila germ plasm to human germ cells. Dev Genes Evol 2003; 213:120-6. 